\title{
Metabolic and ventilatory changes in asthmatic patients during and after exercise
}

\author{
SANDRA D. ANDERSON ${ }^{1}, M$. SILVERMAN, and \\ S. R. W A L K E R \\ Department of Paediatrics and Asthma, Research Council Clinical Pharmacology Unit, \\ Department of Medicine, Institute of Diseases of the Chest, Brompton Hospital, London S.W.3
}

Five asthmatic patients aged 25-30 years were studied during and after 6-8 minutes of steady exercise on both a bicycle ergometer and a treadmill. For each patient the duration of work, oxygen consumption, minute ventilation, and heart rate were similar in each form of exercise.

During exercise all patients had an increase in peak expiratory flow rate. The blood lactate level was higher during bicycle exercise but arterial $\mathrm{PCO}_{2}$ and $\mathrm{pH}$ fell to similar levels during both forms of exercise. There was a rise in arterial oxygen tension in four of the patients during exercise; in one subject arterial oxygen tension fell.

Bronchoconstriction was greater following treadmill exercise in all subjects and was associated with an increase in ventilation/perfusion inequality, as shown by arterial hypoxaemia, an increase in alveolar-arterial oxygen tension gradients, and an increase in physiological dead space. In one subject whose PEFR fell to $25 \%$ of the predicted value $\mathrm{Co}_{2}$ retention occurred. These changes are similar to those found in other forms of acute asthma.

In one subject, during both forms of exercise the mixed expired $\mathrm{PcO}_{2}$ was observed to be higher than the arterial $\mathrm{PCO}_{2}$, thus giving a negative value for physiological dead space. This observation is discussed.

It is now well recognized that in many asthmatic subjects, both adults and children, an acute attack of asthma may be precipitated by exercise (Jones, Buston, and Wharton, 1962; McNeill, Nairn, Millar, and Ingram, 1966). Although these attacks are usually of short duration they may be severe, and arterial hypoxaemia has been reported following exercise (Rebuck and Read, 1968).

No comprehensive report has been made on the metabolic and ventilatory changes occurring in asthmatic subjects during and after an attack of exercise-induced bronchoconstriction (EIB) provoked by a suitable form of exercise under controlled conditions.

Since running provokes more severe bronchoconstriction than does cycling (Anderson, Connolly, and Godfrey, 1971), a factor not taken into account by some workers who have investigated asthmatic subjects only during and after cycling exercise, it was decided to investigate a group of asthmatic subjects to compare the metabolic and ventilatory responses during and after these two

${ }^{1}$ Correspondence: Sandra D. Anderson, Department of Paediatrics, Institute of Diseases of the Chest, London S.W.3 forms of exercise. Comparisons have also been made between changes occurring during an attack of EIB and those occurring during attacks of other forms of asthma which have been reported by other workers.

\section{MATERIALS AND METHODS}

Four men and one woman aged 25-40 years, who had recently been inpatients at the Brompton Hospital, were studied and their physical characteristics are shown in Table I. They all had asthma, as defined by Scadding (1966), and were selected because EIB had been provoked during previous tests in this laboratory. A detailed history was taken from each patient and, before both studies, a careful explanation of the tests was given and consent was obtained in writing.

No patient had taken bronchodilator drugs or disodium cromoglycate within 12 hours, or antihistamines within 24 hours of any test. Corticosteroid treatment was continued in patients 2 and 4.

Each patient performed two exercise tests on different days, one on a bicycle ergometer (Lode) and one on a treadmill (Quinton). The tests were of identical duration for each subject and the order in which the tests were performed was randomized. Spirometry and peak expiratory flow rate (PEFR) 
T A B LE I

ANTHROPOMETRIC DATA AND PREDICTED PEAK EXPIRATORY FLOW RATES

\begin{tabular}{c|c|c|c|c|c}
\hline $\begin{array}{c}\text { Subject } \\
\text { No. }\end{array}$ & Sex & $\begin{array}{c}\text { Age } \\
(\mathbf{y r})\end{array}$ & $\begin{array}{c}\text { Height } \\
(\mathrm{cm})\end{array}$ & $\begin{array}{c}\text { Weight } \\
(\mathbf{k g})\end{array}$ & $\begin{array}{c}\text { Predicted Peak } \\
\text { Flow Rate (1/min) }\end{array}$ \\
\hline 1 & $\mathbf{F}$ & 25 & $174 \cdot 5$ & $58 \cdot 5$ & 490 \\
2 & $\mathbf{M}$ & 28 & 170 & 65 & 590 \\
3 & $\mathbf{M}$ & 30 & 168 & 65 & 575 \\
4 & $\mathbf{M}$ & 30 & 177 & 73 & 620 \\
5 & $\mathbf{M}$ & 29 & 178 & 77 & 615 \\
\hline
\end{tabular}

were measured at rest and these were similar in each individual before both studies.

Before each exercise test, a flexible plastic cannula (Medicut) was placed in the brachial artery under local anaesthesia. After a period of rest, measurements were made over several minutes of heart rate and minute ventilation, and during this time an arterial blood sample $(4 \mathrm{ml})$ was collected in a heparinized syringe. Blood $(3 \mathrm{ml})$ was pipetted into $0.6 \mathrm{M}$ perchloric acid $(2 \mathrm{ml})$ and lactate levels were estimated using a nicotinamide dinucleotide-lactate dehydrogenase system. The measurements were carried out spectrophotometrically (Unicam spectrophotometer SP 500 with Guildford attachments). Blood gas tensions and $\mathrm{pH}$ were measured on the remainder of the sample within one minute of collection using Eschweiler micro-electrodes. The PEFR was measured using a Fleisch pneumotachograph and exercise was then begun at the predetermined level.

On the basis of tests carried out previously, a work load was chosen for the first study which would produce a heart rate of at least 160 beats/minute. For the second study a load was used which was estimated to produce the same heart rate, oxygen consumption, and minute ventilation as in the first study. The duration of each exercise test was 6 minutes in subject 2 and 8 minutes in the other subjects. During exercise, patients breathed through a low-resistance valve of low dead space $(53 \mathrm{ml})$ and the expired gas was flushed continuously through a Tissot spirometer. At 2-minute intervals during exercise and at increasing intervals after exercise, simultaneous collections of mixed expired gas and arterial blood were made. The gas was collected for at least one minute and was immediately analysed for $\mathrm{CO}_{2}$ (URAS-4 infrared analyser) and for $\mathrm{O}_{2}$ (Servomex, paramagnetic oxygen analyser). The analysers were calibrated at the end of each study with gases previously analysed by the micro-scholander method.

During the gas collections measurements were also made of heart rate and minute ventilation. PEFR was measured when each gas collection was completed, the highest of three values being used in the analysis of the results. All data were displayed on an ink-jet chart recorder (Mingograf 81).

Values for normal subjects were taken from Grimby (1962), Matell (1963), Naimark, Wasserman, and McIlroy (1964), Tabakin, Hanson, Merriam, and Caldwell (1964), Jones, McHardy, Naimark, and Campbell (1966), Wasserman, Van Kessel, and Burton (1967),
Cotes (1968), Hermansen and Saltin (1969), and Whipp and Wasserman (1969).

For the statistical analysis, paired sample $t$ tests were used to assess the significance of differences between bicycle and treadmill studies. When $P>0.05$ (two-tailed test) there was said to be no significant difference.

\section{RESULTS}

Because there were some differences between subjects in the response to exercise, individual graphs are given showing changes in PEFR, arterial $\mathrm{Po}_{2}$, arterial $\mathrm{PCO}_{2}$, physiological dead space, and dead space/tidal volume ratio (Figs. 1 to 5).
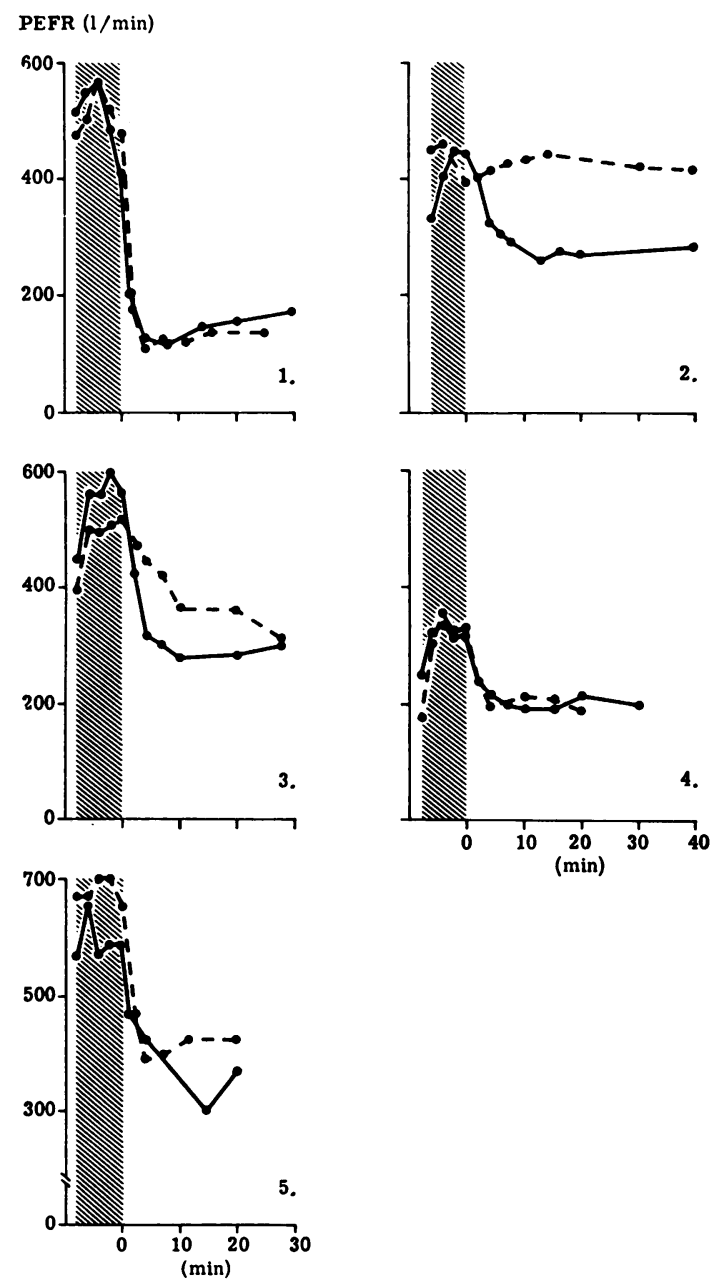

FIG. 1. Changes in peak expiratory flow rate during and after exercise: $\longrightarrow$ treadmill, - . . . - bicycle ergometer. 
T A B L E II

VALUES FOR PEAK EXPIRATORY FLOW RATE AT REST AND CHANGES DURING AND AFTER EXERCISE

\begin{tabular}{|c|c|c|c|c|c|}
\hline & \multicolumn{2}{|c|}{ Pre-exercise PEFR } & \multirow{2}{*}{\begin{tabular}{|c} 
Rise in PEFR \\
during \\
Exercise (\%)
\end{tabular}} & \multirow{2}{*}{\multicolumn{2}{|c|}{$\begin{array}{l}\text { Fall in PEFR } \\
\text { after } \\
\text { Exercise (\%) }\end{array}$}} \\
\hline & $(1 / \mathrm{min})$ & $\%$ Predicted & & & \\
\hline & $\mathbf{T}$ & B & $\mathbf{T}$ & B & $\mathbf{T}$ \\
\hline $\begin{array}{l}\text { Mean } \\
\text { SEM } \\
\text { P }\end{array}$ & $\begin{array}{l}433 \\
79 \\
\text { NS }\end{array}$ & $\begin{array}{l}75 \cdot 5 \quad 72 \cdot 1 \\
13 \cdot 3 \mathrm{NS}^{10 \cdot 0} \\
\text { NS }\end{array}$ & $\begin{array}{c}36 \cdot 4 \\
17 \cdot 2 \\
\text { NS }\end{array}$ & $\begin{array}{l}31 \\
10.8\end{array}$ & $\begin{array}{l}41 \\
10.1 \\
<0.01\end{array}$ \\
\hline
\end{tabular}

$\mathrm{B}=$ bicycle ergometer; $\mathrm{T}=$ treadmill.

T A B L E I I I

MEAN VALUES FOR SOME METABOLIC AND VENTILATORY PARAMETERS AT REST AND DURING THE LAST TWO MINUTES OF EXERCISE

\begin{tabular}{|c|c|c|c|c|}
\hline & $\begin{array}{l}\text { Alveolar- } \\
\text { arterial } \\
\text { Oxygen } \\
\text { Gradient } \\
\text { (mmHg) }\end{array}$ & $\begin{array}{c}\text { Minute } \\
\text { Ventilation } \\
\text { (litres) }\end{array}$ & $\begin{array}{c}\text { Oxygen } \\
\text { Consumption } \\
(\mathrm{ml} / \mathrm{min})\end{array}$ & $\begin{array}{l}\text { Heart Rate } \\
\text { (beats/min) }\end{array}$ \\
\hline & $\mathbf{T}$ & $\mathbf{T}$ & $\mathrm{T}$ & $\mathbf{T}$ \\
\hline $\begin{array}{l}\text { Mean } \\
\text { SEM } \\
\text { P }\end{array}$ & \begin{tabular}{|cc|}
\multicolumn{3}{c|}{ Pre-exercise } \\
$14 \cdot 1$ & $15 \cdot 8$ \\
$6 \cdot 3$ & $2 \cdot 8$ \\
$0.05>\mathrm{P}>0 \cdot 01$
\end{tabular} & $\begin{array}{cl}10.1 & 9.4 \\
1.36 & 2.52 \\
\text { NS } & \end{array}$ & \begin{tabular}{|cc}
293 & 276 \\
$24 \cdot 5$ & $31 \cdot 3$ \\
$\mathrm{NS}$
\end{tabular} & ${ }_{\text {NS }}^{90} \underset{9.8}{97}$ \\
\hline $\begin{array}{l}\text { Mean } \\
\text { SEM } \\
\text { P }\end{array}$ & 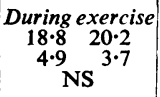 & $\begin{array}{cc}63.1 & 56.5 \\
6.05 & 3 \cdot 73 \\
\text { NS }\end{array}$ & $\begin{array}{cr}1940 & 1928 \\
211 & 146 \\
& \text { NS }\end{array}$ & $\underset{5 \cdot 5}{170} \underset{\text { NS }}{175} 4 \cdot 3$ \\
\hline
\end{tabular}

Where the response to exercise was more uniform, mean results have been given (Tables II and III). Individual and mean results for arterial blood $\mathrm{pH}$ and lactate are given in Table IV.

PEAK EXPIRATORY FLOW RATE There were individual differences in PEFR before exercise (Fig. 1). In all subjects PEFR rose significantly during both forms of exercise, the mean rise being $25 \%$ from the initial value (Table II, Fig. 1). A fall in PEFR from the resting value was greater following exercise on the treadmill in all subjects and the mean difference was significant (paired $t$ test).

VENTILATION (VE), OXYGEN CONSUMPTION $\left(\dot{V}_{2}\right)$, AND HEART RATE VE was generally greater during bicycle exercise but the difference was not significant (Table III). During both forms of exercise VE in relation to $\mathrm{VO}_{2}$ was normal in three subjects and raised in subjects 2 and 5. Ve was similar during recovery from both forms of exercise.

$\mathrm{Vo}_{2}$ and heart rate were not significantly different during bicycle and treadmill exercise (Table III) and were within normal limits.

ARTERIAL OXYGEN TENSION ( $\left.\mathrm{Po}_{2}\right)$ Four of the five subjects showed an increase in arterial $\mathrm{Po}_{2}$ during exercise which was followed by a fall after exer- cise to values lower than the pre-exercise level. One subject (No. 4) had a fall in arterial $\mathrm{Po}_{2}$ during exercise with a subsequent return to his normal resting level after exercise (Fig. 2).
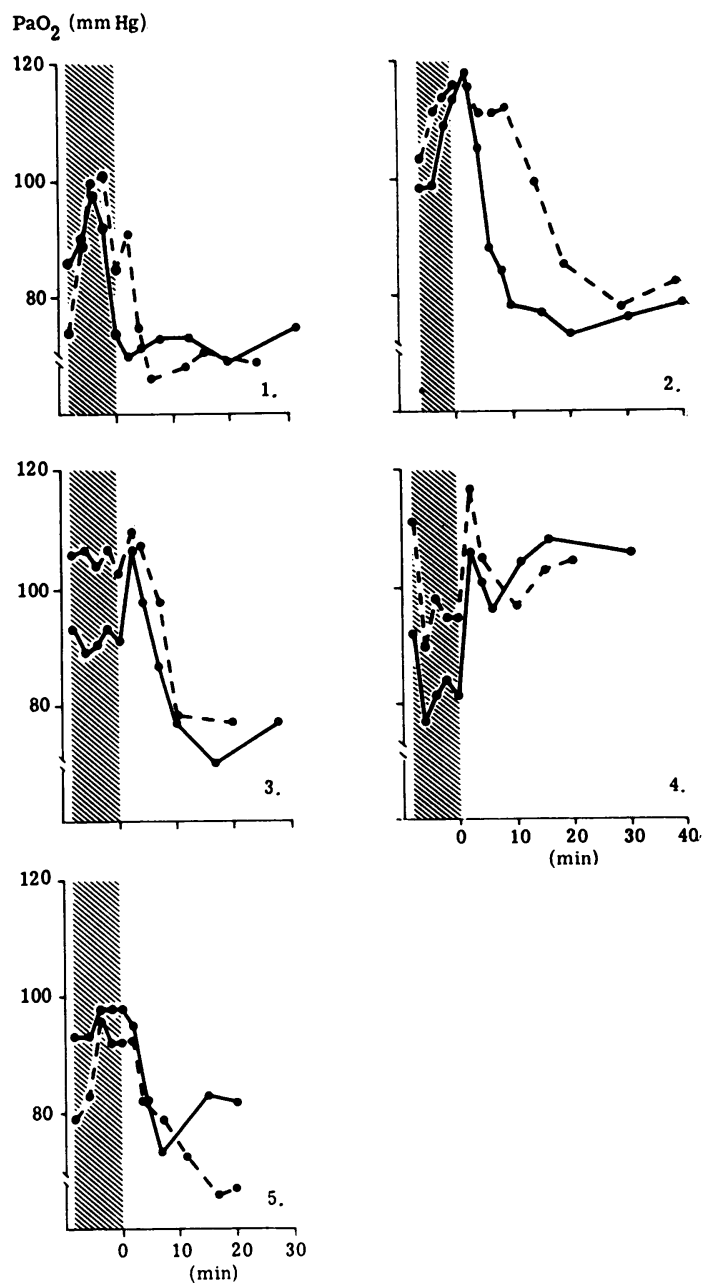

FIG. 2. Changes in arterial oxygen tension during and after exercise. For symbols see Fig. 1.

ARTERIAL CARBON DIOXIDE TENSION ( $\mathrm{PCO}_{2}$ ) Values for arterial $\mathrm{PCO}_{2}$ were variable during exercise but in the last minute of exercise values for arterial $\mathrm{PCO}_{2}$ were lower than pre-exercise values in four of the five subjects (Fig. 3). Following bicycle exercise the arterial $\mathrm{PCO}_{2}$ rose but values were lower than normal and similar to those observed at rest. Following treadmill exercise arterial $\mathrm{PcO}_{2}$ rose above the pre-exercise value in all subjects, though only two subjects increased their 
arterial $\mathrm{PCO}_{2}$ above $44 \mathrm{mmHg}$ and only one subject (No. 1) developed significant $\mathrm{Co}_{2}$ retention (Fig. 3).
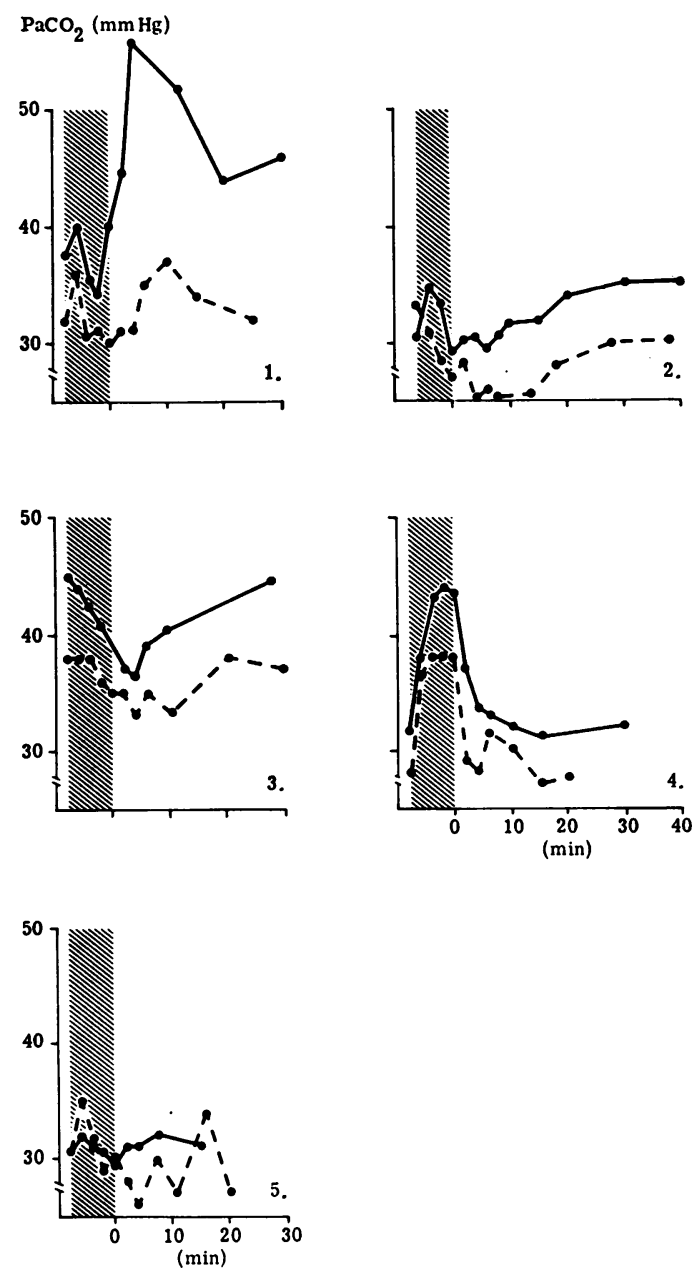

FIG. 3. Changes in arterial carbon dioxide tension during and after exercise. For symbols see Fig. 1.

ALVEOLAR-ARTERIAL OXYGEN GRADIENT At rest alveolar-arterial oxygen gradients were normal in three subjects but moderately raised in subjects 1 and 5. During exercise alveolar-arterial oxygen tension gradients increased above the resting level in all subjects but remained within normal limits (Table III). Following exercise they continued to increase, reaching values higher than normal in all but subject 4. The mean values for alveolararterial oxygen gradients were $33 \mathrm{mmHg}$ after bicycle exercise and $36 \mathrm{mmHg}$ after treadmill exercise.

ARTERIAL PH AND ARTERIAL LACTATE There was a fall of similar magnitude in arterial $\mathrm{pH}$ during both forms of exercise. The arterial $\mathrm{pH}$ reached lower values following bicycle exercise than following treadmill exercise (Table IV) but it returned to normal resting values within 30 minutes after both forms of exercise.

\section{T A B LE IV}

INDIVIDUAL AND MEAN VALUES FOR ARTERIAL $P H$ AND ARTERIAL BLOOD LACTATE DURING AND AFTER

\begin{tabular}{|c|c|c|c|c|c|c|c|}
\hline \multirow{3}{*}{$\begin{array}{l}\text { Subject } \\
\text { No. }\end{array}$} & \multicolumn{3}{|c|}{$\begin{array}{c}\text { During Last Minute of } \\
\text { Exercise }\end{array}$} & \multicolumn{4}{|c|}{ After Exercise } \\
\hline & pH & \multicolumn{2}{|c|}{$\begin{array}{l}\text { Lactate } \\
(\mathrm{mEq} / \mathrm{l})\end{array}$} & \multicolumn{2}{|c|}{$\begin{array}{c}\text { Lowest } \\
\text { pH }\end{array}$} & \multicolumn{2}{|c|}{$\begin{array}{l}\text { Highest } \\
\text { Lactate } \\
\text { (mEq/l) }\end{array}$} \\
\hline & $\mathbf{T}$ & B & $\mathbf{T}$ & B & $T$ & B & $\mathbf{T}$ \\
\hline $\begin{array}{l}1 \\
2 \\
3 \\
4 \\
5\end{array}$ & $\begin{array}{ll}7 \cdot 35 & 7 \cdot 35 \\
7 \cdot 23 & 7 \cdot 25 \\
7 \cdot 35 & 7 \cdot 32 \\
7 \cdot 26 & 7 \cdot 26 \\
7 \cdot 37 & 7 \cdot 38\end{array}$ & $\begin{array}{rr}7.8 & 3 \\
11.7 & 9 \\
7.0 & 4 \\
7.9 & \\
5.0 & 2\end{array}$ & $\begin{array}{l}3 \cdot 8 \\
9 \cdot 2 \\
4 \cdot 1 \\
4 \cdot 8 \\
2 \cdot 4\end{array}$ & $\begin{array}{ll}7 \cdot 28 & 7 \\
7 \cdot 17 & 7 \cdot 33 \\
7 \cdot 28 & ? \\
7 \cdot 36 & ?\end{array}$ & $\begin{array}{l}7 \cdot 31 \\
7 \cdot 24 \\
7 \cdot 41 \\
7 \cdot 34 \\
7 \cdot 41\end{array}$ & $\begin{array}{r}7 \cdot 2 \\
13 \cdot 4 \\
7 \cdot 5 \\
8 \cdot 3 \\
5 \cdot 4\end{array}$ & $\begin{array}{r}3 \cdot 3 \\
10 \cdot 4 \\
3 \cdot 6 \\
4 \cdot 3 \\
2 \cdot 1\end{array}$ \\
\hline $\begin{array}{l}\text { Mean } \\
\text { SEM } \\
\text { P }\end{array}$ & $\begin{array}{c}7 \cdot 31 \quad 7 \cdot 31 \\
0.03 \text { 0.03 } \\
\text { NS }\end{array}$ & $\begin{array}{ll}7.9 & 4 \\
1.09 & 1 \\
0.005> \\
P>0.00\end{array}$ & $\begin{array}{l}4 \cdot 9 \\
1 \cdot 2 \\
> \\
01\end{array}$ & $\begin{array}{l}7.28 \\
0.03 \\
<0.0\end{array}$ & $\begin{array}{l}7 \cdot 34 \\
0 \cdot 03 \\
001\end{array}$ & $\begin{array}{l}8.4 \\
1 \cdot 34 \\
<0\end{array}$ & $\begin{array}{c}4 \cdot 7 \\
1 \cdot 46 \\
001\end{array}$ \\
\hline
\end{tabular}

There was a rise in arterial blood lactate during exercise. This rise was signficantly greater during bicycle exercise than treadmill exercise. It was higher following bicycle exercise than following treadmill exercise (Table IV) but in both cases returned to pre-exercise levels within 30 minutes after exercise.

PHYSIOLOGICAL DEAD SPACE (VD) AND DEAD SPACE/ TIDAL VOLUME RATIO (VD/VT) VD was within normal limits at rest in four subjects; it was raised above the normal predicted value in subject 4 (Fig. 4). During exercise results for VD were variable. Compared with a normal group of subjects performing exercise under similar laboratory conditions (Jones et al., 1966) the VD increased above the upper limit of predicted normal in subject 1 during treadmill exercise and in subject 2 during cycling exercise. VD remained within normal limits during the other exercise tests in these two subjects but in the other three subjects values for VD were lower than expected during at least one form of exercise. One subject (No. 5) had a mixed expired $\mathrm{PCO}_{2}$ marginally higher than arterial $\mathrm{PCO}_{2}$ during at least one collection in both forms of exercise, thus giving a negative value for VD. Following exercise VD increased to values 

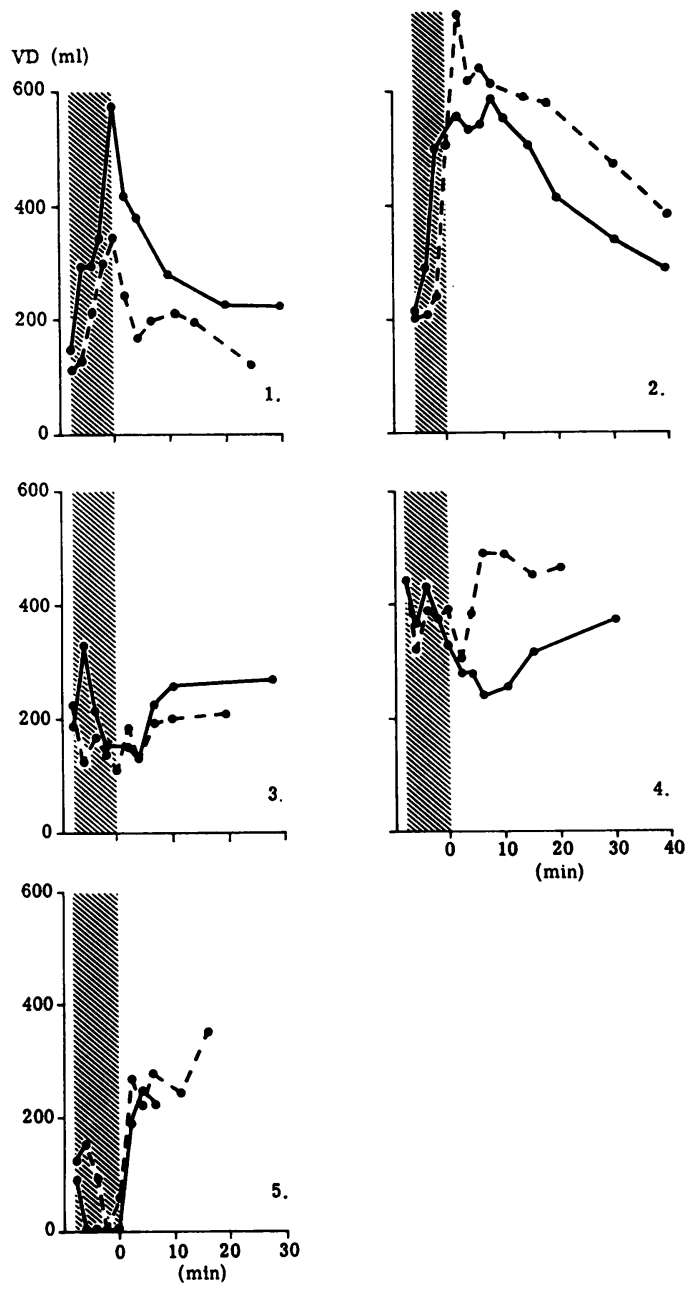

FIG. 4. Changes in physiological dead space during and after exercise. For symbols see Fig. 1.

above the predicted normal and in subjects 2 and 4 values for VD reached two to three times the predicted normal value. VD/VT ratios were near the upper limit of normal (35\%) before exercise. During exercise the ratio fell in all subjects, reaching values which were below the accepted lower limit of normal during at least one form of exercise in all but subject 4 . Following exercise VD/VT ratios rose to values equal to or above the initial value (Fig. 5).

\section{DISCUSSION}

In the present study a marked increase in peak expiratory flow rate occurred in all subjects during
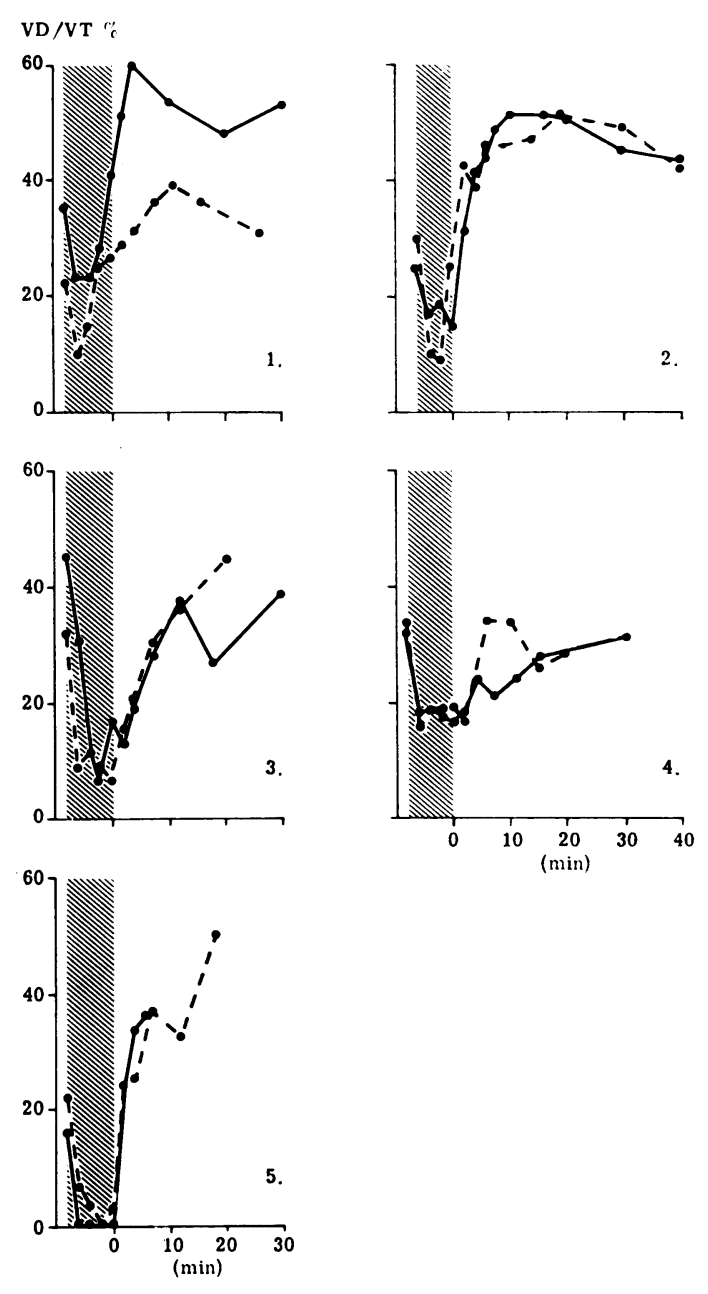

FIG. 5. Changes in physiological dead space/tidal volume ratio during and after exercise. For symbols see Fig. 1.

the first few minutes of exercise. In general this rise in flow rate was associated with an increase in arterial $\mathrm{Po}_{2}$. However, in one subject, arterial $\mathrm{Po}_{2} \stackrel{\sim}{\circ}$ fell on exercise, an observation which could have $N$ important clinical implications. After exercise bronchoconstriction occurred, as demonstrated by a fall in PEFR. The fall in arterial oxygen tension and increase in physiological dead space and alveolar-arterial oxygen gradient observed during the period of bronchoconstriction induced by the exercise were of similar magnitude to changes which have been reported during other forms of acute asthma (Field, 1967; Valabhji, 1968). 
PEAK EXPIRATORY FLOW RATE The rise in PEFR during exercise in the asthmatic subjects in the present study $(25 \%)$ was in keeping with earlier reports (Heimlich, Strick, and Busser, 1966; Anderson et al., 1971). The degree of bronchodilatation found here is significantly greater than the mean rise of PEFR which has been observed in normal subjects during bicycle and treadmill exercise in our own laboratory.

A fall in PEFR of more than $12 \%$ following exercise has not been observed in normal subjects (Anderson et al., 1971) but bronchoconstriction has been reported in asthmatic subjects after exercise (Jones et al., 1962; Jones, Wharton, and Buston, 1963; Jones, N. L., 1966; McNeill et al., 1966). The greater degree of bronchoconstriction which occurred following treadmill exercise confirms earlier reports from this laboratory that running is likely to produce more severe bronchoconstriction than cycling (Anderson et al., 1971).

The bronchoconstriction following exercise could not be explained simply by the lactic acidosis, acidaemia, increase in minute ventilation or change in oxygen tension during exercise, as has been suggested by other authors (Herxheimer, 1946; Irnell and Swartling, 1966; Seaton, Davies, Gaziano and Hughes, 1969; Fisher, Holton, Buxton, and Nadel, 1970; Katz, Whipp, Heimlich, and Wasserman, 1971). In the present study exercise-induced bronchoconstriction was greater following treadmill exercise but lactic acidosis, VE hypocapnia, and arterial $\mathrm{Po}_{2}$ were generally higher following bicycle exercise (Silverman, Anderson, and Walker, 1972).

ARTERIAL OXYGEN TENSION The rise in arterial $\mathrm{Po}_{2}$ in four of our subjects during exercise was of similar magnitude to that observed by Katz et al. (1971) during progressive bicycle exercise but exceeded the rise in arterial $\mathrm{Po}_{2}$ reported in normal subjects (Naimark et al., 1964; Whipp and Wasserman, 1969). This improvement in arterial oxygen tension is analogous to that which occurs during exercise in subjects with chronic bronchitis (Jones, R. S., 1966) and might be expected to result from better distribution of ventilation perfusion ratios in the lungs during exercise (West and Dollery, 1960). Following exercise, as bronchoconstriction developed these four subjects had a fall in arterial oxygen tension. Arterial hypoxaemia has been reported in patients during other forms of acute asthma (Rees, 1966; Tai and Read, 1967; Waddell, Emerson, and Gunstone, 1967; McFadden and Lyons, 1968) but is not observed in normal subjects following moderate exercise (Matell, 1963). Hypoxia is presumably a consequence of the uneven ventilation resulting from increased airways obstruction which occurred following exercise.

Subject 4 differed from the other subjects in that his arterial $\mathrm{Po}_{2}$ fell during both forms of exercise. During bicycle exercise his arterial $\mathrm{Po}_{2}$ fell by 21 $\mathrm{mmHg}$ at a time when his PEFR had risen by $70 \%$. Following exercise the arterial $\mathrm{Po}_{2}$ returned to the initial value, which was within normal limits. In spite of airways obstruction at rest, this subject must have compensated for the uneven distribution of ventilation. During exercise unequal changes in bronchomotor and vasomotor tone may have caused a disturbance in the ventilation perfusion ratios so that arterial hypoxia resulted. Such changes have been reported following isoprenaline inhalation and infusion and have similarly caused some degree of hypoxaemia (Field, 1967; Palmer and Diament, 1967).

ARTERIAL BLOOD LACTATE AND pH The higher blood lactate levels observed during the bicycle exercises are consistent with reports in normal subjects (Wasserman et al., 1967; Hermansen and Saltin, 1969). However, the actual values in four of the asthmatic subjects during cycling were much higher than those observed in normal untrained subjects working at the same oxygen consumption. Two of these subjects also had higher than predicted values for arterial blood lactate during treadmill exercise. The reason for the higher blood lactate values is not known as all the subjects were active and in full employment and two had engaged in sporting activities.

With the exception of subject 5 , values for arterial $\mathrm{pH}$ during both forms of exercise were somewhat lower than those observed in normal subjects working at similar levels (Naimark et al., 1964). The fall in $\mathrm{pH}$ may have resulted from the lactic acidosis. The relatively lower arterial $\mathbf{P C O}_{2}$ during cycling exercise could have compensated for the difference in lactate so that the arterial pH was the same during both forms of exercise (Table IV). It has been suggested that the lactic acidosis and acidaemia occurring during exercise may be the cause of the bronchoconstriction following exercise. However, in the present study the greater lactic acidosis during cycling exercise and the similar degree of acidaemia during both forms of exercise suggest that this is not the case.

Ventilation AND PERfusion Physiological dead space calculated from the Bohr equation using the measured values for arterial $\mathrm{PCO}_{2}$ was variable in this group of subjects during exercise. In subject 5 , values for mixed expired $\mathrm{PCO}_{2}$ were observed to 
be higher than arterial $\mathrm{PcO}_{2}$ on several occasions, thus giving negative values for VD during both forms of exercise (Fig. 4). These observations could not be accounted for by technical errors as the arterial blood was collected over the same period as the mixed expired gas. Similar values were obtained for VD during exercise in this subject on a third and separate exercise test carried out six weeks later. Negative values for VD have been observed previously in normal subjects. Beaudry, Wise, and Seely (1967) reported one subject with a VD of $-13 \mathrm{ml}$ during exercise but did not discuss the finding. Salzano, Bell, Weglicki, and Saltzman (1967) observed a mixed expired $\mathrm{PCO}_{2}$ greater than arterial $\mathrm{PCO}_{2}$ in 86 out of 225 measurements made on normal subjects under hyperbaric and normal pressure conditions. They suggested that the difference may have been due to phasic changes in the arterial $\mathrm{PCO}_{2}$ not revealed by intermittent sampling or that $\mathrm{CO}_{2}$ may be secreted in the lung.

In the present study, if end tidal $\mathrm{PCO}_{2}$ as an estimate for alveolar $\mathrm{PCO}_{2}$ was used instead of arterial $\mathrm{PCO}_{2}$ in the calculation of $\mathrm{VD}$, values for VD close to or above those which would be predicted were obtained. Negative values appeared when the alveolar-arterial $\mathrm{PCO}_{2}$ gradient was greater than that normally observed during exercise. During exercise a $\mathrm{PCO}_{2}$ gradient from alveolar gas to arterial blood usually develops in normal subjects (Matell, 1963; Jones et al., 1966) due to variations in the time constants of lung units. In subjects 1 to 4 the values of this $\mathrm{CO}_{2}$ gradient during exercise approximated to those observed by Matell (1963) and Jones et al. (1966). In subject 5 , who had low or negative values for VD, gradients were far larger than those observed by Matell and Jones, alveolar $\mathrm{PCO}_{2}$ exceeding arterial $\mathrm{PCO}_{2}$ by up to $9.4 \mathrm{mmHg}$, but such values have been reported during treadmill exercise in normal subjects breathing through an expiratory airway obstruction (Hanson, Tabakin, and Levy, 1967). In the presence of a normal difference between end tidal and mixed expired $\mathrm{PCO}_{2}$ these observations suggest that in subject 5 arterial $\mathrm{PCO}_{2}$ was underestimated.

An underestimate of arterial $\mathrm{PCO}_{2}$ could occur if the body temperature during exercise was much higher than the temperature at which the blood was analysed $\left(37^{\circ} \mathrm{C}\right)$. Although body temperature was not measured, the blood temperature of the subject would have had to be $41^{\circ} \mathrm{C}$ to cause an underestimate of these proportions. It has been shown that there is no significant increase in oesophageal temperature in the first 6 to 7 minutes of exercise (Saltin and Hermansen, 1966).
It had been noted that at equilibrium during the plateau rebreathing procedure, gas $\mathrm{PCO}_{2}$ is higher으 than that found in the blood leaving the lungs $\frac{\bar{m}}{\bar{p}}$ during the plateau. This has been described as $\mathbb{\Omega}$ the 'downstream effect' by Jones, Campbell, Edwards, and Wilkoff (1969). It is possible that ${ }^{\text {s }}$ similar blood gas differences on exercise occurred $\vec{\circ}$ during the present study to such a degree that $\overrightarrow{\vec{\omega}}$ arterial $\mathrm{PCO}_{2}$ was less than mixed expired $\mathrm{PCO}_{2}, \stackrel{\omega}{\omega}$ but the precise reason for this difference remains $\vec{x}$ unexplained.

Following exercise arterial $\mathrm{PCO}_{2}$ was always. greater than mixed expired $\mathrm{PCO}_{2}$ and physiological $\stackrel{\odot}{\circ}$ dead space increased in all subjects, generally to $\vec{\infty}$ much higher levels than would be expected ino normal subjects. Similar values have been? observed in patients suffering from acute attacks $z$ of asthma (Field, 1967). In one subject following treadmill exercise the increase in VD was asso- $\frac{\mathbb{D}}{3}$ ciated with alveolar hypoventilation and $\mathrm{Co}_{2}$ retention. This was at a time when the PEFR had $\stackrel{\mathbb{}}{\stackrel{1}{-}}$ fallen to about $25 \%$ of the predicted value. Car- 0 bon dioxide retention has been reported in N asthmatic subjects whose forced expiratory volume in one second had fallen to below $30 \%$ of the predicted value (Tai and Read, 1967; McFadden and Lyons, 1968) and in whom alveolar hypoventilation is occurring due to mechanical limitations to breathing.

\section{CONCLUSION}

Two sorts of response to exercise have beent? demonstrated in the present study, both of which have important clinical implications. In four of으 the subjects, both bicycle ergometer and treadmill exercise caused a return towards normal valuesoof ventilation perfusion relationships, but the acute bronchospasm which followed exercise in these patients caused the same sort of deterioration in function as has been observed previouslyo in acute attacks of asthma. These changes were ${ }_{\supset}$ rapidly relieved by administration of a broncho- dilator aerosol. In one subject, the presence of hypoxaemia during severe exercise constitutes a. potentially greater hazard. Such a patient, whoseN respiratory system has become fully adapted to the presence of some degree of fixed airways obstruction, may be at risk during heavy exercise especially if he uses an isoprenaline aerosol to enable him to incease his effort tolerance, since both may precipitate hypoxia.

We are grateful to Dr. Margaret Turner-Warwick- $\stackrel{\text { D }}{\mathbb{D}}$ the patients in this study were under her care. We $\frac{\rho}{\mathbb{D}}$ would also like to thank Mr. E. Zeidifard for technicale help and Dr. Simon Godfrey for helpful comments. 
This work was supported by Fisons Pharmaceuticals Ltd. (S.D.A. \& M.S.).

\section{REFERENCES}

Anderson, S. D., Connolly, N. M., and Godfrey, S. (1971). Comparison of bronchoconstriction induced by cycling and running. Thorax, 26, 396.

Beaudry, P. H., Wise, M. B., and Seely, J. E. (1967). Respiratory gas exchange at rest and during exercise in normal and asthmatic children. Amer. Rev. resp. Dis., 95, 248.

Cotes, J. E. (1968). Lung Function, 2nd ed., pp. 377, 381. Blackwell Scientific Publications, Oxford.

Field, G. B. (1967). The effects of posture, oxygen, isoproterenol and atropine on ventilation-perfusion relationships in the lung in asthma. Clin. Sci., 32, 279.

Fisher, H. K., Holton, P., Buxton, R. St. J., and Nadel, J. A. (1970). Resistance to breathing during exercise-induced asthma attacks. Amer. Rev. resp. Dis., 101, 885.

Grimby, G. (1962). Exercise in man during pyrogen induced fever. Scand. J. clin. Lab. Invest., 14, Suppl. 67, 1-112.

Hanson, J. S., Tabakin, B. S., and Levy, A. M. (1967). Exercise arterial blood gas and end-tidal gas changes during acute airway obstruction. Resp. Physiol., 3, 64 .

Heimlich, E. M., Strick, L., and Busser, R. J. (1966). An exercise response test in childhood asthma. (Abstract.) J. Allergy, 37, 103.

Hermansen, L., and Saltin, B. (1969). Oxygen uptake during maximal treadmill and bicycle exercise. J. appl. Physiol., 26, 31.

Herxheimer, H. (1946). Hyperventilation asthma. Lancet, 1, 83.

Irnell, L., and Swartling, S. (1966). Maximal expiratory flow at rest and during muscular work in patients with bronchial asthma. Scand. J. resp. Dis., 47, 103.

Jones, N. L. (1966). Pulmonary gas exchange during exercise in patients with chronic airway obstruction. Clin. Sci., 31, 39.

Campbell, E. J. B., Edwards, R. H. T., and Wilkoff, W. G. (1969). Alveolar-to-blood $\mathrm{PCO}_{2}$ difference during rebreathing in exercise. J. appl. Physiol., 27, 356.

, McHardy, G. J. R., Naimark, A., and Campbell, E. J. M. (1966). Physiological dead space and alveolararterial gas pressure differences during exercise. Clin. Sci., 31, 19.

Jones, R. S. (1966). Assessment of respiratory function in the asthmatic child. Brit. med.J., 2, 972.

- Buston, M. H., and Wharton, M. J. (1962). The effect of exercise on ventilatory function in the child with asthma. Brit. J. Dis. Chest, 56, 78.

, Wharton, M. J., and Buston, M. H. (1963). The place of physical exercise and bronchodilator drugs in the assessment of the asthmatic child. Arch. Dis. Childh., 38, 539.
Katz, R. M., Whipp, B. J., Heimlich, E. M., and Wasserman, K. (1971). Exercise-induced bronchospasm, ventilation, and blood gases in asthmatic children. J. Allergy, 47, 148.

Matell, G. (1963). Time-courses of change in ventilation and arterial gas tensions in man induced by moderate exercise. Acta physiol. scand., 58, Suppl. 206, 1-53.

McFadden, E. R., and Lyons, H. A. A. (1968). Arterial-blood gas tension in asthma. New Engl. J. Med., 278, 1027.

McNeill, R. S., Nairn, J. R., Millar, J. S., and Ingram, C. G. (1966). Exercise-induced asthma. Quart. J. Med., 35, 55.

Naimark, A., Wasserman, K., and McIlroy, M. B. (1964). Continuous measurement of ventilatory exchange ratio during exercise. J. appl. Physiol., 19, 644.

Palmer, K. N. V., and Diament, M. L. (1967). Effect of aerosol isoprenaline on blood-gas tensions in severe bronchial asthma. Lancet, 2, 1232.

Rebuck, A. S., and Read, J. (1968). Exercise-induced asthma. Lancet, 2, 429.

Rees, H. A. (1966). Blood gases in asthma. (Abstract.) Proceedings of the Thoracic Society. Thorax, 21, 485.

Saltin, B., and Hermansen, L. (1966). Esophageal, rectal, and muscle temperature during exercise. J. appl. Physiol., 21, 1757.

Salzano, J. V., Bell, W. H., Weglicki, W. B., and Saltzman, H. A. (1967). Metabolic, respiratory and hemodynamic responses to exercise at increased oxygen pressure. Proc. 3rd Symp. Underwater Physiol., edited by C. J. Lambertsen, pp. 351-360. Williams and Wilkins, Baltimore.

Scadding, J. G. (1966). Patterns of respiratory insufficiency. Lancet, 1, 701.

Seaton, A., Davies, G., Gaziano, D., and Hughes, R. O. (1969). Exercise-induced asthma. Brit. med. J., 3, 556.

Silverman, M., Anderson, S. D., and Walker, S. R. (1972). Metabolic changes preceding exercise-induced bronchoconstriction. Brit. med. J., 1, 207.

Tabakin, B. S., Hanson, J. S., Merriam, T. W., and Caldwell, E. J. (1964). Hemodynamic response of normal men to graded treadmill exercise. J. appl. Physiol., 19, 457.

Tai, E., and Read, J. (1967). Blood-gas tensions in bronchial asthma. Lancet, 1, 644.

Valabhji, P. (1968). Gas exchange in the acute and asymptomatic phases of asthma breathing air and oxygen. Clin. Sci., 34, 431.

Waddell, J. A., Emerson, P. A., and Gunstone, R. F. (1967). Hypoxia in bronchial asthma. Brit. med.J., 2, 402.

Wasserman, K., van Kessel, A. L., and Burton, G. (1967). Interaction of physiological mechanisms during exercise. J. appl. Physiol., 22, 71.

West, J. B., and Dollery, C. T. (1960). Distribution of blood flow and ventilation-perfusion ratio in the lung, measured with radioactive $\mathrm{Co}_{2}$. J. appl. Physiol., 15, 405 .

Whipp, B. J., and Wasserman, K. (1969). Alveolar-arterial gas tension differences during graded exercise. $J$. appl. Physiol., 27, 361. 